\title{
COMPARISON OF POLYMERASE CHAIN REACTION-RESTRICTION ENZYME ANALYSIS METHOD AND DNA SEQUENCE ANALYSIS RESULTS IN THE IDENTIFICATION OF NON- TUBERCULOUS MYCOBACTERIA
}

\author{
ÖZGÜR APPAK ${ }^{1 *}$, SELÇUK TÜRKEL ${ }^{2}$, NURAN ESEN ${ }^{1}$ and AYŞE AYDAN ÖZKÜTÜK ${ }^{1}$ \\ ${ }^{1}$ Department of Medical Microbiology, Dokuz Eylul University, İzmir, Turkey \\ ${ }^{2}$ Department of Medical Microbiology, Training and Research Hospital, Aksaray \\ University, Aksaray, Turkey
}

(Received: 9 February 2018; accepted: 3 April 2018)

\begin{abstract}
The typing of non-tuberculous mycobacteria (NTM) is important from a clinical and epidemiological perspective. The polymerase chain reaction-restriction enzyme analysis (PRA) method and DNA sequence analysis method were utilized to target a gene region that codes the $65-\mathrm{kDa}$ heat-shock protein for typing 150 suspected NTM samples isolated from the respiratory tract. Mycobacterium abscessus, Mycobacterium xenopi, Mycobacterium fortuitum, and Mycobacterium peregrinum were most frequently found by both methods. Six isolates that could not be defined by the PRA method were defined as Nocardia cyriacigeorgica, Nocardia abscessus, and Mycobacterium intracellulare by DNA sequence analysis. Discordance between the results of the two methods was observed for only one isolate. The isolate that was defined as Mycobacterium gordonae type 6 by the PRA method was defined as Mycobacterium senegalense by sequence analysis. The PRA method is simple and gives rapid results. Compared with DNA sequence analysis, it gives consistent and reliable results up to a ratio of $90 \%$. DNA sequence analysis is the gold standard method in which all strains can be defined. However, given our laboratory conditions, its disadvantage is that it takes longer to reach a diagnosis than through the PRA method.
\end{abstract}

Keywords: non-tuberculous mycobacteria, DNA sequence analysis, restriction enzyme analysis, heat-shock protein

\section{Introduction}

Non-tuberculous mycobacteria (NTM) represents a large number of nonpathogenic mycobacterial species other than the Mycobacterium tuberculosis

\footnotetext{
*Corresponding author; E-mail: ozgurappak@yahoo.com.tr
} 
complex (MTC) (Mycobacterium bovis, M. bovis Bacille Calmette-Guérin, Mycobacterium africanum, Mycobacterium canetti, Mycobacterium microti, Mycobacterium pinnipedii, and Mycobacterium caprae) and Mycobacterium leprae [1].

Today, more than 170 types of NTM are found intensely in nature, especially in soil and water sources, including drinking water systems (http:// www.bacterio.net/mycobacterium.html). These may lead to diseases especially in people who undergo immune-suppressive treatment or who suffer from immune deficiency, but NTM infections can also be observed in people with normal immune systems. The NTM can infect many systems, primarily respiratory, and can lead to various clinical pictures [2]. The prevalence of pulmonary NTMs varies among countries, but it is increasing worldwide and becoming an important public health problem, especially for elderly people. Although the exact reason for this increase is not known, it can be explained by the increase in the patient population sensitive to NTM, the use of advanced molecular-based tests, the rise in environmental mycobacterial infection sources, and more awareness among clinicians against NTMs. Because NTMs can be found everywhere as saprophytes, their isolation from the respiratory tract does not show that they are always causative agents. Therefore, the diagnosis should be verified clinically, microbiologically, and radiologically [3-5].

NTMs should be defined at a species level, because they are resistant to classic antituberculosis drugs and the different types have different susceptibilities to antibiotics. Additionally, the definition is necessary to enable the collection of epidemiological data. In this study, the polymerase chain reaction (PCR)-restriction enzyme analysis (PRA) method and DNA sequence analysis method were used to define samples isolated from the respiratory tract that were not MTC and were suspected of being NTM. The objective was to compare the results of the two methods and evaluate the epidemiological data collected in our hospital over a specific period.

\section{Materials and Methods}

\section{Study group}

We studied 185 NTM suspect samples that were detected not to be MTC from respiratory tract samples, between 2004 and 2010, at the Dokuz Eylul University Hospital's Mycobacteriology Laboratory. The study was funded by the university and confirmed by its ethics committee. Isolates from 150 patients were included in the study, after excluding the isolates of repeated samples and those 
that were not reproduced after passage. The following were used as quality control strains: Mycobacterium intracellulare type 1 (ATCC 13950), Mycobacterium abscessus tip 1 (ATCC 19977), Mycobacterium fortuitum type 1 (ATCC 6841), Mycobacterium gordonae type 1 (ATCC 14470), Mycobacterium scrofulaceum type 1 (ATCC 19981), Mycobacterium szulgai (ATCC 35799), Mycobacterium kansasii type 1 (ATCC 12478), and M. tuberculosis H37Rv.

\section{Identification of NTM}

The MTC and NTM distinction was made by p-nitro- $\alpha$-acetylamino- $\beta$ hydroxypropiophenone (NAP) and p-nitro benzoic acid. Phenotypic and conventional methods were used for those that could not be differentiated. An amount of $0.5 \mathrm{ml}$ was taken from BACTEC 12B and MGIT 960 bottles that belonged to NTM-suspected samples, their fresh passage was made to the Löwenstein-Jensen (LJ) medium and their growth feature was controlled.

\section{DNA extraction}

Colonies from the LJ mediums, where the growth was detected, were added to a 1-ml physiological saline solution and centrifuged at $11,000 \times \mathrm{g}$ for $1 \mathrm{~min}$. A $250-\mu 11 \times$ TE tampon (10 mM Tris, $1 \mathrm{mM}$ EDTA, $\mathrm{pH}$ 8.0) was added to the precipitate and mixed using vortex agitation. Then, it was again centrifuged at $11,000 \times g$ for $1 \mathrm{~min}$ and a $250-\mu \mathrm{l} 1 \times \mathrm{TE}$ tampon was added to the precipitate and incubated at $95^{\circ} \mathrm{C}$ for $10 \mathrm{~min}$. The centrifuge processing was repeated and the supernatant portion was maintained at $-20^{\circ} \mathrm{C}$ as a DNA extract until inclusion in the study.

\section{Polymerase chain reaction (PCR)}

The heat-shock protein 65 (hsp65) gene region of NTM was reproduced by the PCR reaction. The mixture, whose total volume was $50 \mu \mathrm{l}$, included the isolated DNA sample, $\mathrm{dH}_{2} \mathrm{O}, \mathrm{MgCl}_{2}(25 \mathrm{mM})$, dNTP $(10 \mathrm{mM}), 10 \times$ Buffer, Primer 1 (Tb11; 5'-ACCAACGATGGTGTGTCCAT-3'), Primer 2 (Tb12; 5'-CTTGTCGAACCGCATACCCT-3'), and hot start taq DNA polymerase. This mixture was placed in a "thermal cycler" device (Techne TC-412, Bioblock, Illkirch, France) and subjected to initial denaturation at $95^{\circ} \mathrm{C}$ for $5 \mathrm{~min}$. Then, 40 cycles were applied: $94^{\circ} \mathrm{C}$ for $1 \mathrm{~min}, 60^{\circ} \mathrm{C}$ for $1 \mathrm{~min}, 72^{\circ} \mathrm{C}$ for $1 \mathrm{~min}$, and again for $10 \mathrm{~min}$. The reaction was stopped at $4{ }^{\circ} \mathrm{C}$ and the amplification products were shown at gel electrophoresis [6]. 
A 50-base pair (bp) DNA reagent was loaded on the first and the last wells as an indicator of molecular magnitude and PCR was loaded on the other wells. After applying electrophoresis at $130 \mathrm{~V}$ for $45 \mathrm{~min}$, the gel was viewed on a UV transilluminator.

\section{Restriction enzyme analysis}

For both enzymes (BstE II and Hae III), a 10- $\mu$ l PCR product was added to the mixtures that contained $12.0 \mu \mathrm{l} \mathrm{dH}_{2} \mathrm{O}, 2.5 \mu \mathrm{l} 5 \times$ buffer, and $0.5 \mu \mathrm{l}$ enzyme. The mixture that contained BstE II was maintained at $60{ }^{\circ} \mathrm{C}$ for $1 \mathrm{~h}$ and the mixture that contained Hae III was maintained at $37^{\circ} \mathrm{C}$ for $1 \mathrm{~h}$. After the cutoff period, the patterns were viewed at $4 \%$ metaphor gel. The results are available in http://app. chuv.ch/prasite/index.html.

\section{DNA sequence analysis}

A $40-\mu 1$ portion of the PCR products equaling $441 \mathrm{bp}$ in length at agarose gel electrophoresis, at a suitable clearness and viewed as pure band, were saved at $2-8{ }^{\circ} \mathrm{C}$ and sent to Korea for purification and double-sided sequencing (Macrogen Inc., Korea). The Tb11 and Tb12 primers used at PCR reaction were used for the sequencing process. The results were e-mailed to us as chromotogram files in abl file format and converted to fasta format by the BioEdit (Biological sequence alignment editor; Ibis Biosciences, Inc., Canada) program and recorded. These sequences were compared with the reference mycobacteria hsp65 gene region downloaded from Genbank (National Center for Biotechnology Information, National Library of Medicine, USA) and were aligned using the BioEdit program. The DNA sequences in aligned fasta format were analyzed using the Basic Local Alignment Search Tool (National Library of Medicine, USA) program, and 150 isolates were defined at the species level.

\section{Results}

Table I shows a distribution by years of 150 patients' samples, which were not MTC, but were detected to have NTM growth. About 42.7\% (64 out of 150) of the isolates belonged to female patients. The sampling distribution was $64(42.7 \%)$ sputum, 73 (48.6\%) bronchial lavage, 11 (7.3\%) bronchoalveolar lavage, and 2 $(1.3 \%)$ tracheal secret.

When the sequences obtained by the DNA sequence analysis were compared with the standard sequences at the GenBank, 51 of the isolates showed 
Table I. Distribution by years of isolates isolated from clinical samples defined as MTC and NTM

\begin{tabular}{lcccc}
\hline Date (year) & $\begin{array}{c}\text { Number } \\
\text { of MTC }\end{array}$ & $\begin{array}{c}\text { Number } \\
\text { of NTM }\end{array}$ & $\begin{array}{c}\text { Number of NTM } \\
\text { included in the study }\end{array}$ & $\begin{array}{c}\text { Number of samples } \\
\text { arriving at laboratory }\end{array}$ \\
\hline 2004 & 46 & 31 & 20 & 1,789 \\
2005 & 80 & 10 & 4 & 2,239 \\
2006 & 94 & 15 & 13 & 2,230 \\
2007 & 99 & 38 & 35 & 2,630 \\
2008 & 55 & 50 & 46 & 2,514 \\
2009 & 83 & 15 & 12 & 2,750 \\
2010 & 64 & 26 & 150 & 2,648 \\
Total & 521 & 185 & 20,800 \\
\hline
\end{tabular}

Note: MTC: Mycobacterium tuberculosis complex; NTM: non-tuberculous mycobacteria.

$100 \%$ compatibility, 94 showed $99 \%, 1$ showed $98 \%, 3$ showed $97 \%$, and 1 showed $95 \%$. Out of 14 different microorganisms that were detected,we had 12 different NTM types and 2 different Nocardia types. The most isolated NTM type was M. abscessus with 69 (46\%), whereas the least-defined NTM types were Mycobacterium porcinum, Mycobacterium avium, and Mycobacterium senegalense with one isolate each $(0.7 \%)$.

The PRA method could not define 6 of the 150 isolates. M. abscessus type 1 was the most isolated NTM with 69 isolates (46\%) (Figures 1 and 2). The six isolates that could not be defined by PRA were defined by the DNA sequence analysis as Nocardia cyriacigeorgica (3/6), Nocardia abscessus (2/6), and $M$. intracellulare $(1 / 6)$. The isolate defined as $M$. gordonae type 6 by PRA was defined as M. senegalense by sequence analysis (Table II). The distribution by years of the defined isolates can be seen in Table III.

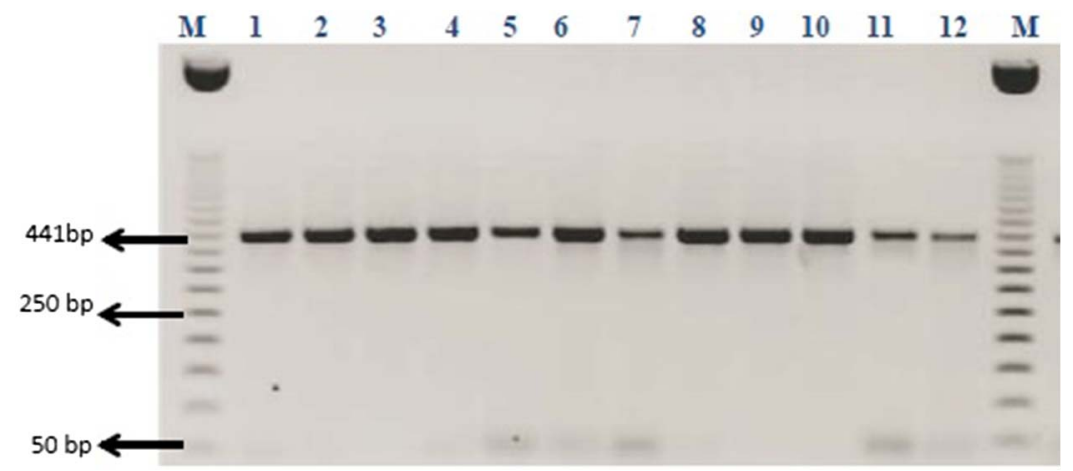

Figure 1. PCR bands views obtained from NTMs. M: marker (50 bp), 1-12 wells; study samples (expected band size: $441 \mathrm{bp}$ ) 


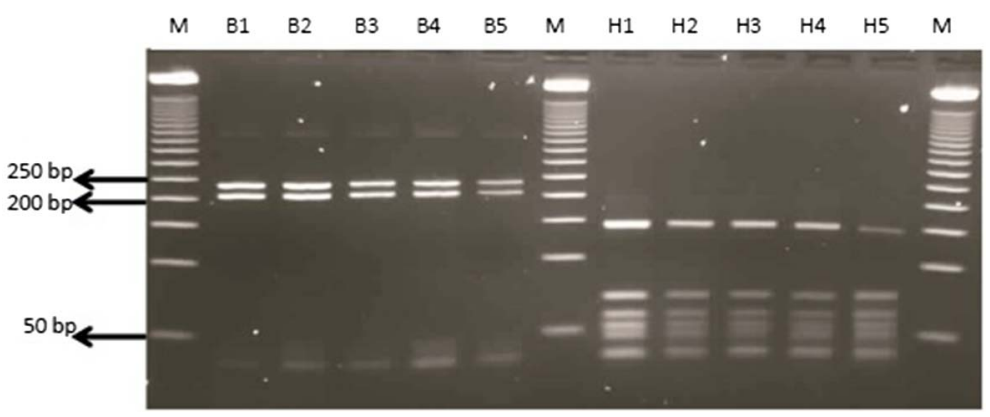

Figure 2. PCR-restriction enzyme analysis cutting patterns. M: marker (50 bp); B: band patterns of BstE II enzyme cutting products; $\mathrm{H}$ : band patterns of Hae III enzyme cutting products; $\mathrm{BI}$ and $\mathrm{H} 1$ : KK2 [Mycobacterium abscessus type 1(ATCC 19977)] cutting patterns, for BstE II enzyme 235-201 bp, forHae III enzyme 145-70-60 bp. Other wells; study samples

Table II. Comparison of results of PRA and DNA sequence analysis

\begin{tabular}{|c|c|c|}
\hline PRA results & $\begin{array}{l}\text { DNA sequence } \\
\text { analysis results }\end{array}$ & $\begin{array}{l}\text { Number of defined } \\
\text { isolates }[n(\%)]\end{array}$ \\
\hline M. abscessus type 1 & M. abscessus & $69(46 \%)$ \\
\hline M. xenopi type 1 & M. xenopi & $26(17.3 \%)$ \\
\hline $\begin{array}{l}\text { M. fortuitum type } 1, M \text {. fortuitum } \\
\text { s. acetamidolyticum type } 1\end{array}$ & M. fortuitum & $13(8.7 \%)$ \\
\hline $\begin{array}{l}\text { M. porcinum type } 1, M \text {. septicum type } 1 \text {, } \\
\text { M. peregrinum tip } 2\end{array}$ & M. peregrinum & $13(8.7 \%)$ \\
\hline $\begin{array}{l}\text { M. porcinum type } 1, \text { M. septicum type } 1 \text {, } \\
\text { M. peregrinum type } 2\end{array}$ & M. porcinum & $1(0.7 \%)$ \\
\hline M. intracellulare type 1, M. chimaera type 1 & M. intracellulare & $5(3.3 \%)$ \\
\hline $\begin{array}{l}\text { M. simiae type } 5, M \text {. lentiflavum type } 1 \text {, } \\
\text { M. florentinum type } 1\end{array}$ & M. lentiflavum & $5(3.3 \%)$ \\
\hline$M$. genavense type $2, M$. simiae type 1 & M. simiae & $4(2.7 \%)$ \\
\hline $\begin{array}{l}\text { M. colombiense type } 1, M \text {. avium s. avium } \\
\text { type } 2\end{array}$ & M. avium & $1(0.7 \%)$ \\
\hline M. avium s. avium type 1 & M. avium izolat & $2(1.3 \%)$ \\
\hline \multicolumn{3}{|l|}{ M. avium s. Paratuberculosis type 1} \\
\hline \multicolumn{3}{|l|}{ M. avium s. Silvaticum type 1} \\
\hline $\begin{array}{l}\text { M. massiliense type } 1, \text { M. bolletii type } 1 \text {, } \\
\text { M. abscessus type } 2\end{array}$ & M. bolletii & $2(1.3 \%)$ \\
\hline M. chelonae type 1 & M. chelonae type & $2(1.3 \%)$ \\
\hline Unidentified 2 isolate & Nocardia abscessus & $2(1.3 \%)$ \\
\hline Unidentified 3 isolate & Nocardia cyriacigeorgica & $3(2 \%)$ \\
\hline Unidentified 1 isolate & M. intracellulare & $1(0.7 \%)$ \\
\hline M. gordonae type 6 & M. senegalense & $1(0.7 \%)$ \\
\hline Total & & $150(100 \%)$ \\
\hline
\end{tabular}

Note: PRA: PCR-restriction enzyme analysis. 
Table III. Distribution by years of the defined isolates

\begin{tabular}{lcccccccr}
\hline Identified isolates & 2004 & 2005 & 2006 & 2007 & 2008 & 2009 & 2010 & Total \\
\hline M. abscessus & 6 & 3 & 12 & 16 & 26 & 5 & 1 & 69 \\
M. xenopi & 1 & - & - & 8 & 10 & 5 & 2 & 26 \\
M. peregrinum & - & - & - & - & 2 & 1 & 10 & 13 \\
M. fortuitum & 6 & 1 & - & 3 & 3 & - & - & 13 \\
M. intracellulare & 1 & - & - & 5 & - & - & - & 6 \\
M. simiae & - & - & - & 1 & 2 & - & 1 & 4 \\
M. lentiflavum & 2 & - & - & - & 2 & - & 1 & 5 \\
M. avium & 1 & - & - & - & - & 1 & 1 & 3 \\
N. cyriacigeorgica & 3 & - & - & - & - & - & - & 3 \\
N. abscessus & - & - & - & 2 & - & - & - & 2 \\
M. chelonae & - & - & - & - & - & - & 2 & 2 \\
M. bolletii & - & - & - & - & - & - & 2 & 2 \\
M. senegalense & - & - & - & - & 1 & - & - & 1 \\
M. porcinum & - & - & 1 & - & - & - & - & 1 \\
Total & 20 & 4 & 13 & 35 & 46 & 12 & 20 & 150 \\
\hline
\end{tabular}

\section{Discussion}

The biochemical tests are not suitable for routine usage in the definition of NTM because they are not practical, require a long time, can only distinguish certain types from each other, and are inadequate in a definition of new mycobacteria types. Nowadays, in-house or commercial molecular-based tests are frequently used in defining types of mycobacteria. The cutting patterns obtained by the BstE II and Hae III enzymes are type specific and allow for the definition of many mycobacteria that are clinically important. The PRA method is used by many laboratories for being easy, fast, and repeatable [6, 7]. Some commercial systems that use DNA probe technology, such as the AccuProbe system (Hologic GenProbe, San Diego, CA), the INNO-LiPA Mycobacteria system (Fujirebio Europe, Ghent, Belgium), and the GenoType Mycobacterium system (Hain Lifescience, Nehren, Germany), are used in the definition of NTMs. However, some probes used in the commercial systems are not $100 \%$ specific and in addition to what is declared by producers, some cross-reactions can be observed $[8,9]$. Sequence analysis is the reference method in the definition of mycobacteria and, for this purpose, the $16 \mathrm{~S}$ rRNA, hsp65, ITS, gyrB, recA, and rpoB gene regions are targeted. Common properties of these gene regions are that they exist in all mycobacteria and include sequences that are well protected from mutation and are variable specific to each type. 16S rRNA and hsp65 are the most important and most frequently used gene regions $[10,11]$. In this study, we compared the 
results obtained by the hsp65 PRA method with the results of the reference method, DNA sequence analysis.

Our DNA sequence analysis results with the PRA method were compatible with $95.3 \%(143 / 150)$ and incompatible with $0.6 \%(1 / 150)$. The study by Chimara et al. [12] indicated $90.3 \%$ compatibility between the two methods, and the PRA method defined only $1.2 \%$ of the samples incorrectly. Sajduda et al. evaluated 38 reference strains by the PRA method and observed that the dimensions of the cutting patterns were $7 \mathrm{bp}$ smaller than the sequence analysis. However, they observed that the repeatability of PRA patterns and the accuracy level of the results were high. In the same study, they blindly applied the 64 strains to the traditional biochemical tests, the commercial INNO-LiPA method, and DNA sequence analysis. In the biochemical tests, they found that 14 of the 64 isolates were defined incorrectly, but that correct results were yielded with $78 \%$. Despite that, they observed that the results obtained by the PRA method were compatible with INNO-LiPA by $89 \%$ and by DNA sequence analysis by 93.3\% [13]. Gürtler et al. [14] identified mycobacteria species with 16S-23S rDNA (ISR)-restriction fragment site polymorphisms rapidly between 2 days and 4 weeks and all identifications were found to be compatible with DNA sequencing. Important advantages of the PRA method are that it can be applied easily, gives results quickly, and obtains over $90 \%$ conformity in the results. However, a big disadvantage of the PRA method is that the band length is evaluated visually, which makes standardization and evaluation of small band patterns (especially cut by Hae III) difficult. Furthermore, a single base change can lead to the appearance or disappearance of a new cutting area [15]. For instance, a point mutation in one of the cutting pattern regions can shift the typical PRA model of M. malmoense to a M. marinum-specific PRA model [16]. The parasite website used for interpreting the PRA cutting patterns is helpful. However, it does not use the real dimension of manual cutting patterns, but instead uses the patterns reported by publications, which may lead to problems in evaluation. Although the PRA method is useful for many types, it cannot be used for the taxonomy of new types [17]. The restriction enzymes used in this study caused the production of identical cutting patterns for different mycobacteria types (for instance, $M$. porcinum type $1, M$. septicum type $1, M$. peregrinum type 2, BstE II 235-210 bp, and Hae III 140-125-100 bp). Therefore, changing these restriction enzymes with more distinctive enzymes seems necessary for a definite distinction.

Özçolpan et al. [18] defined ten different types in their sequence analysis study that targeted hsp65 and 16S rRNA in the definition of 101 NTM isolates. M. porcinum (39.60\%), Mycobacterium lentiflavum (35.65\%), and M. abscessus $(5.64 \%)$ were the most isolated types. A sequence analysis carried out in four 
centers in Turkey defined 17 different types in 90 NTM isolates; $M$. gordonae (23\%), M. abscessus (14\%), and M. lentiflavum (10\%) were determined to be the most frequently isolated types [19]. Babalık et al. [20] examined 75 NTM cases, $43 \%$ of which were defined by the hsp65 PRA method, and M. abscessus (28\%), M. avium complex (25\%), and M. kansasii (16\%) were the most frequently seen NTMs. Velayeti et al. analyzed 96 articles that mentioned 1,751 NTM isolates in the Middle Eastern countries and found that M. fortuitum was among the slowgrowing NTMs and $M$. avium complex was among the fast-growing NTMs. In the same study, they analyzed 21 articles published in Turkey between 1993 and 2013 and the frequency order of 280 NTM isolates were defined as follows: M. avium complex (54/280), M. gordonae (53/280), M. fortuitum (48/280), and M. abscessus (45/280) [21]. The NTMs predominantly exist in soil and water, environments that are basic sources of infection. Therefore, the reason for the differences of dominant types between laboratories is considered to be a result of different environmental conditions [22].

In this study, six isolates considered to be NTM could not be defined by the PRA method. These samples for during the period 2004-2007 were routinely processed by the LJ and BACTEC 460 TB systems, and the NAP test was used to make the MTC and NTM distinction. Five isolates suspected of being NTM, which were proved not to be MTC by the NAP test, did not present any band pattern with the BstE II (440-0-0) and Hae III (0-0-0-0) enzymes used in the PRA. The bacteriological and clinical properties of Nocardias are similar to those of mycobacteria and should additionally be considered for a differential diagnosis. The mycobacteria can be distinguished from each other easily and quickly by BstE II cutting patterns with the PRA, but some publications indicate that other actinomycetes that also contain Nocardias do not have BstE II cutting patterns. It has been reported that this property can be used to define nocardias. However, Brunello et al. [23] have shown that the BstE II (440-0-0) cutting patterns of some mycobacteria (Mycobacterium confluentis, Mycobacterium gilvum, Mycobacterium tusciae, Mycobacterium brumae, Mycobacterium duvalii, M. Szulgai, and Mycobacterium gadium) did not exist, just as they did not exist in Nocardia. Besides, revealing that Nocardia ignorata and Nocardia cerradoensis have BstE II cutting patterns makes one think that the estimated definition can be inconvenient. In addition, the fact that Hae III patterns are different than the algorithm defined by Chimara et al. [12] explains why Nocardias are not defined due to the enzymes used in the PRA method. At 235-120-100 bp, cutting patterns were observed in the other isolate undefined by the PRA method, the BstE II enzyme, but could not be defined because the Hae III and band patterns were not observed. The sequence analysis defined it as M. intracellulare. Sequence analysis is superior to the PRA in its ability to define these types. 
The isolate defined as M. gordonae type 6 by the PRA method was defined as $M$. senegalense (99\% compatible with the reference sequence) by sequence analysis. The internet site prasite defines four types of $M$. senegalense. While $B s t E$ II cutting patterns of $M$. senegalense type 2 and $M$. senegalense type 6 are the same (235/130/85 bp), their Hae III cutting patterns are different (140/125/ $60 / 50$ bp and 140/120/95 bp, respectively). M. gordonae can easily be obtained from fresh water, water installations, and laboratory taps. A slow-growing mycobacteria is generally considered a contaminant [5]. M. senegalense, however, is a fast-growing mycobacteria and generally leads to infections affecting cattle in East Africa. It is reported to have caused catheter-related bacteremia for a patient with immune deficiency and soft tissue infection related to an aquarium glass cut in a normal healthy child [24, 25]. Although we do not have the patient's clinical data, defining it as $M$. senegalense or wrongly as $M$. gordonae type 6 would not create a problem for the patient as these do not cause any infection in the respiratory tract.

It is important to know the culture positivity ratios in mycobacteriology laboratories. If the ratios are higher than expected, the laboratory supervisor should take note. Successive positivity in the samples coming from the bronchoscopy unit, with the same factor isolated, could signal a problem in the sterilization of endoscopic material [26]. In addition, the NTMs may lead to pseudo-positivity in the cultures by contamination of the tampons and water used in laboratories. If these pseudo-infections can be detected, people can be prevented from unnecessary treatments.

The lack of evidence related to person-to-person infection and the fact that people generally get infected by NTMs from the environment presents an important problem concerning the studies about the epidemiology of NTMs. People become exposed to NTMs by drinking tap water, swimming, or inhaling aerosols while taking a shower. To understand whether the NTMs detected in this study are causative agents or contaminants, and their epidemiological meanings, more comprehensive clinical work is needed.

In summary, the PRA method is an easily applicable method that gives results quickly. Compared with DNA sequence analysis, it gives over $90 \%$ compatible and reliable results. For NTM-suspected samples undefined by the PRA, other microorganisms should be considered. DNA sequence analysis is the gold standard method and has defined all our strains. However, as it is not a method we apply directly in our laboratory, a disadvantage is that it takes longer to reach a diagnosis than through the PRA method. For patient management and follow-up treatment, the NTM results should be considered with the clinical findings. 


\section{Conflict of Interest}

The authors declare no conflict of interest.

\section{References}

1. Cousins, D. V., Bastida, R., Cataldi, A., Quse, V., Redrobe, S., Dow, S., Duignan, P., Murray, A., Dupont, C., Ahmed, N., Collins, D. M., Butler, W. R., Dawson, D., Rodri'guez, D., Loureiro, J., Romano, M. I., Alito, A., Zumarraga, M., Bernardelli, A.: Tuberculosis in seals caused by a novel member of the Mycobacterium tuberculosis complex: Mycobacterium pinnipedii sp. nov. Int J Syst Evol Microbiol 53, 1305-1314 (2003).

2. Guglielmetti, L., Mougari, F., Lopes, A., Raskine, L., Cambau, E.: Human infections due to nontuberculous mycobacteria: The infectious diseases and clinical microbiology specialists' point of view. Future Microbiol 10, 1467-1483 (2015).

3. Shah, N. M., Davidson, J. A., Anderson, L. F., Lalor, M. K., Kim, J., Thomas, H. L., Lipman, M., Abubakar, I.: Pulmonary Mycobacterium avium-intracellulare is the main driver of the rise in non-tuberculous mycobacteria incidence in England, Wales and Northern Ireland, 2007-2012. BMC Infect Dis 16, 195 (2016).

4. Piersimoni, C., Scarparo, C.: Extrapulmonary infections associated with nontuberculous mycobacteria in immunocompetent persons. Emerg Infect Dis 15, 1351-1358 (2009).

5. Griffith, D. E., Aksamit, T., Brown-Elliott, B. A., Catanzaro, A., Daley, C., Gordin, F., Holland, S. M., Horsburgh, R., Huitt, G., Lademarco, M. F., Iseman, M., Oliver, K., Ruoss, S., von Reyn, C. F., Wallace, R. J., Winthrop, K.: An official ATS/IDSA statement: Diagnosis, treatment, and prevention of nontuberculous mycobacterial diseases. Am J Respir Crit Care Med 175, 367-416 (2007).

6. Telenti, A., Marchesi, F., Balz, M., Bally, F., Bottger, E. C., Bodmer, T.: Rapid identification of mycobacteria to the species level by polymerase chain reaction and restriction enzyme analysis. J Clin Microbiol 31, 175-178 (1993).

7. Verma, A. K., Kumar, G., Arora, J., Singh, P., Arora, V. K., Myneedu, V. P., Sarin, R.: Identification of mycobacterial species by PCR restriction enzyme analysis of the hsp65 gene an Indian experience. Can J Microbiol 61, 293-296 (2015).

8. Tortoli, E.: Microbiological features and clinical relevance of new species of the genus Mycobacterium. Clin Microbiol Rev 27, 727-752 (2014).

9. Tortoli, E., Pecorari, M., Fabio, G., Messinò, M., Fabio, A.: Commercial DNA-probes for mycobacteria incorrectly identify a number of less frequently encountered species. J Clin Microbiol 48, 307-310 (2010).

10. Kim, H., Kim, S. H., Shim, T. S., Kim, M. N., Chae, G. T., Bai, G. H., Park, Y. G., Lee, S. H., Cha, C. Y., Kook, Y. H., Kim, B. J.: Differentiation of Mycobacterium species by analysis of the heat-shock protein 65 gene (hsp65). Int J Syst Evol Microbiol 55, 1649-1656 (2005).

11. McNabb, A., Eisler, D., Adie, K., Amos, M., Rodrigues, M., Stephens, G., Black, W. A., Isaac-Renton, J.: Assessment of partial sequencing of the 65-kilodalton heat shock protein 
gene (hsp65) for routine identification of Mycobacterium species isolated from clinical sources. J Clin Microbiol 42, 3000-3011 (2004).

12. Chimara, E., Ferrazoli, L., Ueky, S. Y., Martins, M. C., Durham, A. M., Arbeit, R. D., Leao, S. C.: Reliable identification of mycobacterial species by PCR-restriction enzyme analysis (PRA)-hsp65 in a reference laboratory and elaboration of a sequence-based extended algorithm of PRA-hsp65 patterns. BMC Microbiol 8, 48-54 (2008).

13. Sajduda, A., Martin, A., Portaels, F., Palomino, J. C.: hsp65 PCR-restriction analysis (PRA) with capillary electrophoresis in comparison to three other methods for identification of Mycobacterium species. J Microbiol Methods 80, 190-197 (2010).

14. Gürtler, V., Harford, C., Bywater, J., Mayall, B. C.: Direct identification of slowly growing Mycobacterium species by analysis of the intergenic 16S-23S rDNA spacer region (ISR) using a GelCompar II database containing sequence based optimization for restriction fragment site polymorphisms (RFLPs) for 12 enzymes. J Microbiol Methods 64, 185-99 (2006).

15. Ringuet, H., koua-Koffi, C., Honore, S., Varnerot, A., Vincent, V., Berche, P., Gaillard, J. L., Pierre-Audigier, C.: hsp65 sequencing for identification of rapidly growing mycobacteria. J Clin Microbiol 37, 852-857 (1999).

16. Nolte, O., Haag, H., Hafner, B.: A mutation in the 65, 000 Dalton heat shock proteingene, commonly used for molecular identification of non-tuberculous mycobacteria, leads to the misidentification of Mycobacterium malmoense as Mycobacterium marinum. Mol Cell Probes 19, 275-277 (2005).

17. Pourahmad, F., Thompson, K. D., Adams, A., Richards, R. H.: Comparative evaluation of polymerase chain reaction-restriction enzyme analysis (PRA) and sequencing of heat shock protein 65 (hsp65) gene for identification of aquatic mycobacteria. J Microbiol Methods 76, 128-135 (2009).

18. Özçolpan, O. O., Sürücüoğlu, S., Özkütük, N., Çavuşoğlu, C.: Distribution of nontuberculous mycobacteria isolated from clinical specimens and identified with DNA sequence analysis. Mikrobiyol Bul 49, 484-493 (2015).

19. Günaydin, M., Yanik, K., Eroglu, C., Sanic, A., Ceyhan, I., Erturan, Z., Durmaz, R.: Distribution of nontuberculous mycobacteria. Ann Clin Microbiol Antimicrob 12, 33 (2013).

20. Babalık, A., Kuyucu, T., Ordu, E. N., Ernam, D., Partal, M., Köksalan, K.: Non-tuberculous mycobacteria infection: 75 cases. Tuberk Toraks 60, 20-31 (2012).

21. Velayati, A. A., Rahideh, S., Nezhad, Z. D., Farnia, P., Mirsaeidi, M.: Nontuberculous mycobacteria in Middle East: Current situation and future challenges. Int J Mycobacteriol 4, 7-17 (2015).

22. Cook, J. L.: Nontuberculous mycobacteria: Opportunistic environmental pathogens for predisposed hosts. Br Med Bull 96, 45-59 (2010).

23. Brunello, F., Ligozzi, M., Cristelli, E., Bonora, S., Tortoli, E., Fontana, R.: Identification of 54 mycobacterial species by PCR-restriction fragment length polymorphism analysis of the hsp65 gene. J Clin Microbiol 39, 2799-2806 (2001).

24. Oh, W. S., Ko, K. S., Song, J. H., Lee, M. Y., Ryu, S. Y., Taek, S., Kwon, K. T., Lee, J. H., Peck, K. R., Lee, N. Y.: Catheter associated bacteremia by Mycobacterium senegalense in Korea. BMC Infect Dis 5, 107 (2005). 
25. Talavlikar, R., Carson, J., Meatherill, B., Desai, S., Sharma, M., Shandro, C., Tyrrell, G. J., Kuhn, S.: Mycobacterium senegalense tissue infection in a child after fish tank exposure. Can J Infect Dis Med Microbiol 22, 101-103 (2011).

26. Middleton, A. M., Chadwick, M. V., Gaya, H.: Disinfection of bronchoscopes, contaminated in vitro with Mycobacterium tuberculosis, Mycobacterium and Mycobacterium chelonae in sputum, using buffered peracetic ("Nu-Cidex") acid solution. J Hosp Infect 37, 137-143 (1997). 